\title{
KAJIAN KUAT LEKAT PADA BETON MUTU TINGGI MEMADAT MANDIRI DENGAN METAKAOLIN
}

\author{
Wibowo'), Antonius Mediyanto²), Nur'arina Ardini3) \\ 1) Pengajar Fakultas Teknik, Prodi Teknik Sipil, Universitas Sebelas Maret \\ 2) Pengajar Fakultas Teknik, Prodi Teknik Sipil, Universitas Sebelas Maret \\ 3) Mahasiswa Fakultas Teknik, Prodi Teknik Sipil, Universitas Sebelas Maret \\ Jl. Ir. Sutami 36A, Surakarta 57126; Telp. 0271-634524. \\ Email: arina1747@gmail.com
}

\begin{abstract}
Infrastructure development is increasing, then create new innovations. One of innovations is high strength self compactiong concrete (HSSCC). This type of concrete has a high compressive strength and can compact without a vibrator. Concrete usually has a low tensile strength, then need involve reinforce steel to withstand tensile force in section concrete which obtain tensile force. The concrete must has bond strength with the reinforce steel for working synergistically. Metakaolin is used in this research as a cement replacement to improve the quality of concrete to shore up tensile moments. The method is used is experimental and parameter that are studied in this reseacrh are bond strength and workability (filling ability) of HSSCC. The specimen are used in the form of cylinder diameter $7.5 \mathrm{~cm}$, beight $15 \mathrm{~cm}$ and reinforce steel diameter $10 \mathrm{~mm}$. Based on this research, metakaolin increases bod strength of concrete at 28 days old. The addition metakaolin at $22.5 \%$ reached the maximum point of bond strength and split tensile strength. All over addition of metakaolin decreased workability, cement replacement with metakaolin up from 12.5\% fulfills fillingability based on EFNARC 2002. The addition of metakaolin at $22.5 \%$ and $27.5 \%$ mixture of concrete can't tested of fillingability (workability less).
\end{abstract}

Keywords: high strength self compacting concrete, metakaolin, bond strength, workability, filling ability

\section{ABSTRAK}

Pembangunan infrastruktur semakin pesat melahirkan inovasi. Salah satu inovasi adalah beton mutu tinggi memadat mandiri. Beton ini memiliki kuat tekan yang tinggi dan dapat memadat tanpa bantuan alat penggetar. Beton cenderung memiliki kuat tarik rendah, maka perlu baja tulangan untuk menahan gaya tarik. Beton juga harus memiliki kuat lekat terhadap baja tulangan agar bekerja dengan sinergis. Metakaolin pada penelitian ini digunakan sebagai pengganti semen untuk meningkatkan kualitas beton terhadap momen tarik. Metode yang digunakan dalam penelitian ini adalah eksperimental dan parameter yang dikaji adalah kuat lekat dan workabilitas (sifat filling ability) dari beton mutu tingi memadat mandiri. Benda uji yang digunakan berbentuk silinder berdiameter $7,5 \mathrm{~cm}$, tinggi $15 \mathrm{~cm}$ dan baja ulir diameter $10 \mathrm{~mm}$. Berdasarkan penelitian, metakaolin meningkatkan kuat lekat pada umur beton 28 hari. Pada kadar metakaolin 22,5\% kuat lekat mencapai titik maksimum. Penambahan metakaolin menurunkan workabilitas, penggantian semen dengan metakaolin kadar 12,5\% dan seterusnya tidak memenuhi parameter filling ability berdasarkan EFNARC 2002. Pada penambahan metakaolin kadar 22,5\% dan 27,5\% campuran beton tidak dapat diuji parameter filling ability (campuran beton tidak workabilitas).

Kata Kunci: beton mutu tinggi memadat mandiri, metakaolin, kuat lekat, workabilitas, filling ability

\section{PENDAHULUAN}

Kebutuhan pembangunan semakin pesat melahirkan banyak inovasi baru pada beton untuk meningkatkan kualitas dan mutu beton. Salah satunya adalah dikembangkannya beton jenis High Strength Self Compacting Concrete (HSSCC) beton yang memiliki kualitas mutu tinggi dengan kemudahan pengerjaan yang baik juga.

Mengacu pada penelitian sebelumnya, penambahan metakaolin sebagai bahan pengganti semen digunakan untuk meningkatkan kualitas beton HSSCC, dan mengurangi kelemahan yang terdapat pada beton konvensional tetapi menurunkan workabilitas. Metakaolin bertindak sebagai pozzolan yang sangat reaktif dan memberikan campuran mortar dan beton dengan sifat mekanik yang dapat meningkatkan kekuatannya (misalnya kuat tekan, kuat tarik, dan kuat lentur), serta permeabilitas yang berkurang (Cabrera, 2000).

Beton memiliki kuat tekan tinggi cenderung memiliki kuat tarik rendah. Beton perlu ditambahkan baja tulangan karena tulangan memiliki daya tarik, lentur, dan tekan yang sangat besar. Pada beton bertulang, baja tulangan ini sangat dibutuhkan untuk menahan momen pada bagian penampang beton yang retak akibat tidak mampu menahan gaya tarik. Beton juga harus memiliki kuat lekat terhadap tulangan agar bekerja dengan sinergis. 
Kuat lekat sering diabaikan dalam penghitungan desain, padahal sifat tersebut merupakan hal penting yang mempengaruhi ukuran beton, besar retakan yang terjadi, panjang penyaluran baja dalam balok beton dan pemakaian baja yang efisien. Penambahan metakaolin sebagai pengganti semen diharapkan mampu dapat mengatasi kompleksitas yang ada di kalangan konstruksi.

\section{LANDASAN TEORI}

Beton mutu tinggi (High Strength Concrete) beton dengan kekuatan yang cukup tinggi atau diatas kekuaran standart yang mana hal tersebut dipengaruhi dari beberapa hal seperti, FAS (faktor air semen), kualitas agregat, bahan tambah, dan kualitas dari pembuatan beton tersebut (Prayitno, 2014).

Self Compacting Concrete (SCC) merupakan beton yang mampu mengalir dengan beratnya sendiri yang dapat dicetak pada bekisting dengan tingkat penggunaan alat pemadat yang sangat sedikit atau tidak memerlukan pemadatan. Beton ini memanfaatkan pengaturan ukuran agregat, porsi agregat, dan zat admixture berupa superplastizicer untuk mencapai kekentalan khusus yang memungkinkannya mengalir sendiri tanpa bantuan alat pemadat (Kukun Rusyandi, 2012).

Bahan tambah pozzolan seperti fly ash, silica fume, metakaolin, dan abu sekam telah digunakan sebagai bahan tambah atau pengganti semen karena dapat meningkatkan kekuatan dan ketahanan beton dibandingkan dengan semen portland biasa (Tjokrodimuljo, 2007).

Metakaolin sebagai salah satu jenis pozzolan yang rata-rata pertikelnya lebih kecil daripada partikel semen. Metakaolin bekerja mengisi ruang antar butiran semen, sehingga secara fisik memperkuat ikatan antar partikel. Metakaolin bereaksi secara optimal dengan kristal kalsium hidroksida (sisa proses hidrasi) menjadi kalsium silikat (bahan perekat beton) dan kalsium aluminat hidrat (Sambowo, 2002).

\section{Kuat Lekat Beton}

Pengujian kuat lekat (pull out test) menggunakan Universal Testing Macbine (UTM). Berdasarkan SNI 03-4809-1998, Tegangan lekat bekerja sepanjang baja tulangan yang tertanam di dalam masa beton, sehingga total gaya yang harus dilawan sebelum batang baja tercabut keluar dari masa beton adalah sebanding lurus luas selimut baja tulangan yang tertanam dikali dengan kuat lekat antara beton dengan baja tulangan. Pengujian kuat lekat dapat diperoleh dari Persamaan 1 dan dapat dilihat pada Gambar 1.

$f^{\prime} \mathrm{b} \quad=\frac{\mathrm{P}}{\mathrm{Ld} \times \pi \times \mathrm{Db}}$.

(1)

dengan: $\mathrm{P}=$ Beban $(\mathrm{N})$

$\mathrm{L}_{\mathrm{d}}=$ Panjang Penyaluran $(\mathrm{mm})$

$\mathrm{d}_{\mathrm{b}}=$ Diameter Baja $(\mathrm{mm})$

$f^{\prime}{ }_{\mathrm{b}}=$ Tegangan Lekat (Mpa)

Kuat lekat antara baja tulangan dengan beton dipengaruhi oleh beberapa faktor (Nawy, 1986), yaitu:

1. Efek kualitas beton dan kuat tarik tekannya.

2. Efek mekanisme penjangkaran ujung tulangan.

3. Diameter tulangan.

4. Adhesi antara beton dan baja tulangan.

5. Efek gripping (memegang) sebagai akibat dari susut pengeringan beton di sekeliling tulangan, dan saling geser antara tulangan dengan beton disekelilingnya.

Pada baja tulangan ulir, selain adhesi, gripping dan friksi, lekatan antara beton dan tulangan dibentuk oleh interlocking. Interlocking mempunyai peran terbesar antara beton dan ulir tulangan yang tidak cepat hilang saat terjadi slip. Panjang penyaluran $\left(l_{d}\right)$ menentukan tahanan terhadap tergelincirnya tulangan. Untuk lebih jelas dilhat pada Gambar 2.

Panjang penyaluran adalah panjang penambatan yang di perlukan untuk mengembangkan tegangan leleh dalam tulangan merupakan fungsi dari tegangan leleh baja, diameter tulangan dan tegangan lekat. Menurut SNI 28472013 menentukan bahwa panjang penyaluran untuk batang tulangan baja tarik deformasian dan tulangan rangkai las seperti Persamaan 2.

$\mathrm{L}_{\mathrm{d}} \quad=\mathrm{L}_{\mathrm{db}} \mathrm{x}$ faktor modikasi.

Keterangan:

$\mathrm{L}_{\mathrm{d}} \quad=$ panjang penyaluran 
$\mathrm{L}_{\mathrm{db}}$ $=$ panjang penyaluran dasar

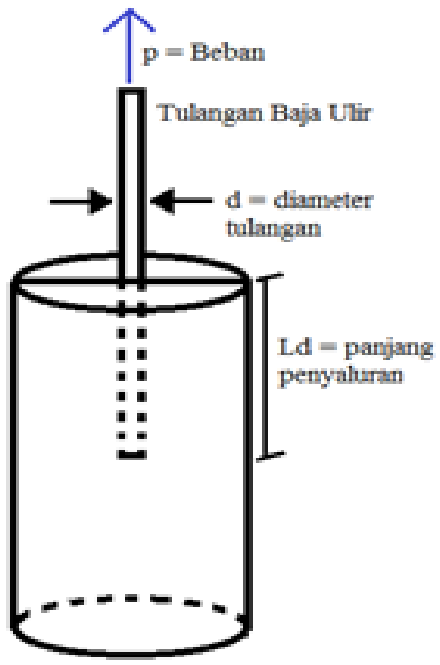

Gambar 1 Sketsa Uji Kuat Lekat

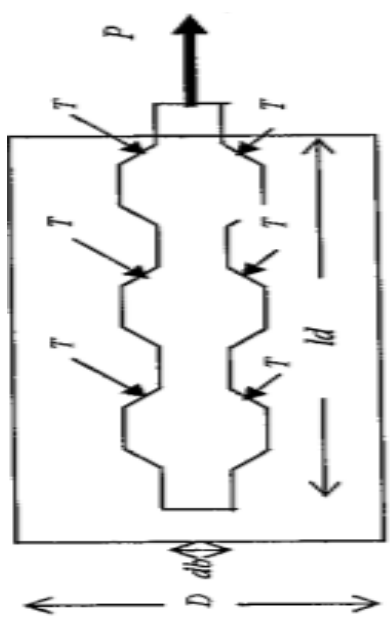

Gambar 2 Mekanisme Gaya Tegangan Lekat Beton dengan Tulangan Ulir.

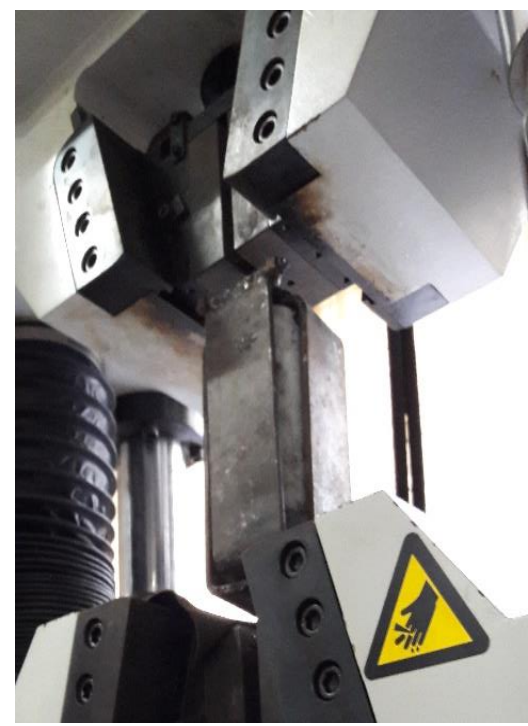

Gambar 3 Pengujian Kuat Lekat

\section{METODE PENELITIAN}

Penelitian ini menggunakan metode eksperimental untuk mengkaji kuat lekat, dan workabilitas (filling ability) beton mutu tinggi memadat mandiri terhadap variasi komposisi metakaolin sebagai bahan pengganti semen. Kuat lekat beton menggunakan Universal Testing Machine (UTM) pada beton umur 28 hari. Workabilitas dengan parameter filling ability dilakukan pada beton segar dengan uji slump flow. Benda uji berbentuk silinder dengan diameter 7,5 cm dan tinggi $15 \mathrm{~cm}$. Komposisi metakaolin yang digunakan sebesar 0\%;12,5\%;17,5\%; 22,5\%; dan 27,5\%. Benda uji berjumlah 3 buah untuk masing-masing komposisi metakaolin dan total benda uji adalah 15 buah. Bentuk benda uji dapat dilihat jelas pada Gambar 4.

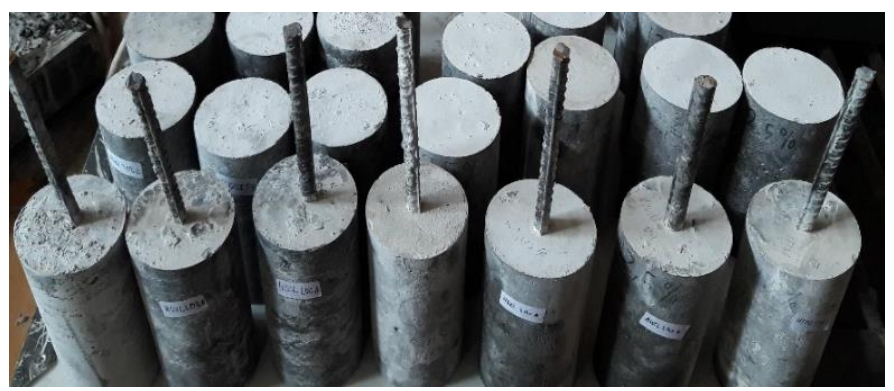

Gambar 4 Benda Uji Untuk Pengujian Kuat Lekat

\section{Mix Design}

Beton mutu tinggi memadat mandiri dengan variasi komposisi metakaolin harus memiliki komposisi material penyusun beton yang sesuai dengan proporsi campuran beton agar sesuai dengan parameter beton memadat mandiri. Mix design mengacu pada peraturan EFNARC 2005 dan penelitian sebelumnya Ahmad, Emir 2017, menggunakan FAS 0,27 dengan superplasticizer Viscocrete 1003 sebanyak 1,7\% dari berat semen. Rekapitulasi mix design beton dapat dilihat pada Tabe1 1.

Tabel 1. Rekapitulasi Mix Design Beton

\begin{tabular}{|c|c|c|c|c|c|c|}
\hline Benda Uji & $\begin{array}{l}\text { Agg. Halus } \\
\left(\mathrm{kg} / \mathrm{m}^{3}\right)\end{array}$ & $\begin{array}{l}\text { Agg. Kasar } \\
\left(\mathrm{kg} / \mathrm{m}^{3}\right)\end{array}$ & $\begin{array}{c}\text { Semen } \\
\left(\mathrm{kg} / \mathrm{m}^{3}\right)\end{array}$ & $\begin{array}{c}\text { Metakaolin } \\
\left(\mathrm{kg} / \mathrm{m}^{3}\right)\end{array}$ & $\begin{array}{c}\text { Superplasticizer } \\
\left(1 \mathrm{lt} / \mathrm{m}^{3}\right)\end{array}$ & $\begin{array}{l}\text { Air } \\
\left(1 \mathrm{t} / \mathrm{m}^{3}\right)\end{array}$ \\
\hline HSSCC-MK0 & 921,13 & 765,98 & 600,00 & 0,00 & 10,20 & 162,00 \\
\hline HSSCC-MK12,5 & 914,64 & 760,59 & 525,00 & 75,00 & 10,20 & 162,00 \\
\hline HSSCC-MK17,5 & 912,04 & 758,43 & 495,00 & 105,00 & 10,20 & 162,00 \\
\hline HSSCC-MK22,5 & 909,44 & 756,27 & 465,00 & 135,00 & 10,20 & 162,00 \\
\hline
\end{tabular}




\begin{tabular}{lllllll}
\hline HSSCC-MK27,5 & 906,85 & 754,11 & 435,00 & 165,00 & 10,20 & 162,00 \\
\hline
\end{tabular}

\section{ANALISIS DATA DAN PEMBAHASAN}

\section{Pengujian Kuat Tarik Baja Tulangan}

Pada Tabel 2 didapat diameter pengenal $\left(d_{p}\right)$ tulangan ulir yang dipakai pada penelitian ini sebesar 9,63 mm. Kuat tarik baja ulir D10 diketahui bahwa kualitas baja yang dipakai sebagai tulangan pada uji kuat lekat beton, tegangan putus rerata baja ulir D10 sebesar 549,31 MPa merupakan baja keras BJ 55 (PBI 1971).

Tabel 2. Rekapitulasi Hasil Pengujian Kuat Tarik Baja Tulangan

\begin{tabular}{|c|c|c|c|c|c|c|c|c|c|}
\hline $\begin{array}{c}\text { Benda } \\
\text { Uji }\end{array}$ & $\begin{array}{c}\text { Berat } \\
\text { (kg) }\end{array}$ & $\begin{array}{c}\text { Panjang } \\
(\mathrm{m})\end{array}$ & $\begin{array}{c}\mathrm{G} \\
(\mathrm{kg} / \mathrm{m})\end{array}$ & $\begin{array}{c}d_{p}=12,8 \sqrt{ } \mathrm{g} \\
(\mathrm{mm})\end{array}$ & $\begin{array}{c}d_{p} \text { rerata } \\
(\mathrm{mm})\end{array}$ & $\begin{array}{c}\mathbf{A} \\
\left(\mathrm{mm}^{2}\right)\end{array}$ & $\begin{array}{c}\mathbf{P} \\
(\mathbf{N})\end{array}$ & $\begin{array}{c}\mathrm{Fu}=\mathrm{P} / \mathrm{A} \\
(\mathrm{MPa})\end{array}$ & $\begin{array}{c}\text { Fu Rerata } \\
(\mathrm{MPa})\end{array}$ \\
\hline A & 0,155 & 0,274 & 0,566 & 9,63 & \multirow{3}{*}{9,63} & 72,79 & 39290 & 539,74 & \multirow{3}{*}{549,31} \\
\hline $\mathrm{B}$ & 0,157 & 0,278 & 0,565 & 9,62 & & 72,67 & 40350 & 555,24 & \\
\hline $\mathrm{C}$ & 0,163 & 0,288 & 0,566 & 9,63 & & 72,83 & 40270 & 552,94 & \\
\hline
\end{tabular}

\section{Metakaolin}

Metakaolin merupakan pozzolan yang reaktif. Penggunaan metakaolin memiliki efek yang sangat besar pada hidrasi semen portland. Hasil pengujian metakolin dapat dilihat pada Tabel 3.

Tabel 3. Pengujian XRF Metakaolin

\begin{tabular}{llcllc}
\multicolumn{1}{c}{ Formula } & $\mathbf{Z}$ & Concentration & \multicolumn{1}{c}{ Formula } & $\mathbf{Z}$ & Concentration \\
\hline $\mathrm{SiO} 2$ & 14 & $61,97 \%$ & $\mathrm{La} 2 \mathrm{O} 3$ & 57 & $0,13 \%$ \\
\hline $\mathrm{Al} 2 \mathrm{O} 3$ & 13 & $16,34 \%$ & $\mathrm{MnO}$ & 25 & $0,08 \%$ \\
\hline $\mathrm{NaO} 2$ & 11 & $7,92 \%$ & $\mathrm{SrO}$ & 38 & $0,06 \%$ \\
\hline $\mathrm{CaO}$ & 20 & $4,31 \%$ & $\mathrm{CeO} 2$ & 58 & $0,05 \%$ \\
\hline $\mathrm{Fe} 2 \mathrm{O} 3$ & 26 & $2,01 \%$ & $\mathrm{ZrO} 2$ & 40 & $0,05 \%$ \\
\hline $\mathrm{P} 2 \mathrm{O} 5$ & 15 & $1,58 \%$ & $\mathrm{BaO}$ & 56 & $0,04 \%$ \\
\hline $\mathrm{K} 2 \mathrm{O}$ & 19 & $1,58 \%$ & $\mathrm{SnO} 2$ & 50 & $0,02 \%$ \\
\hline $\mathrm{MgO}$ & 12 & $1,22 \%$ & $\mathrm{~V} 2 \mathrm{O} 5$ & 23 & $0,02 \%$ \\
\hline $\mathrm{SO} 3$ & 16 & $1,14 \%$ & $\mathrm{Ga} 2 \mathrm{O} 3$ & 31 & $0,01 \%$ \\
\hline $\mathrm{Cl}$ & 17 & $1,00 \%$ & $\mathrm{Bi} 2 \mathrm{O} 3$ & 83 & $0,01 \%$ \\
\hline $\mathrm{TiO} 2$ & 22 & $0,36 \%$ & $\mathrm{Nd} 2 \mathrm{O} 3$ & 60 & $0,01 \%$ \\
\hline $\mathrm{K}$ & 12 & & & & $01 \%$ \\
\hline
\end{tabular}

Ketika semen portland terhidrasi, biasanya 20-30\% dari massa pasta menghasilkan kalsium hidrat $\mathrm{Ca}(\mathrm{OH})_{2}$ yang mudah bereaksi dengan asam sulfat. Namun saat metakaolin digunakan, metakaolin bereaksi cepat dengan senyawa $\mathrm{Ca}(\mathrm{OH})_{2}$ yang baru terbentuk, menghasilkan kalsium silikat hidrat tambahan yaitu perekat tambahan diharapkan dapat menambahkan kuat tekan beton dan mengurangi efek merugikan dari sisa proses hidrasi.

\section{Workability (filling ability)}

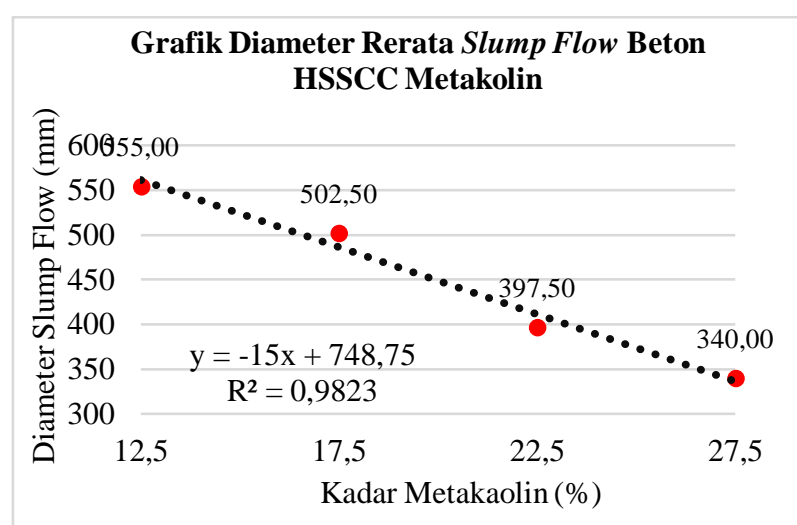

Gambar 5 Grafik Diameter Rerata Slump Flow

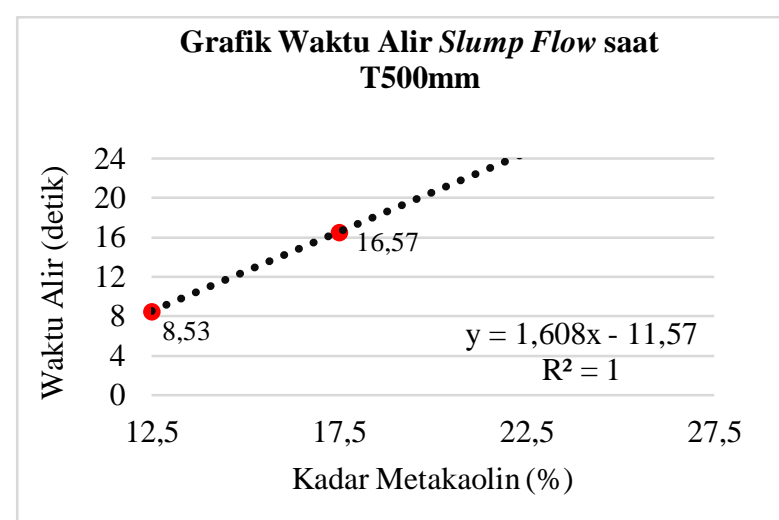

Gambar 6 Grafik Waktu Aliran (T500mm) 
Gambar 5 dan 6 dapat dilihat bahwa diameter sebaran mengecil dan waktu aliran semakin lama seiring bertambahnya komposisi metakaolin sebagai pengganti semen. Pada penambahan kadar metakaolin 22,5\% dan 27,5\% tidak dapat mengalir hingga $500 \mathrm{~mm}$ sehingga tidak mendapatkan hasil waktu aliran slump flow. Beton menjadi lebih kental disebabkan oleh penambahan metakaolin. Metakaolin diperoleh dengan termal aktivasi kaolin. Aktivasi ini menyebabkan hilangnya banyak air dalam partikelnya menyebabkan metakaolin bersifat menyerap air sehingga beton dengan bahan tambah metakaolin akan mengalami penurunan workabilitas (fillingability).

\section{Hasil Pengujian Kuat Lekat Beton}

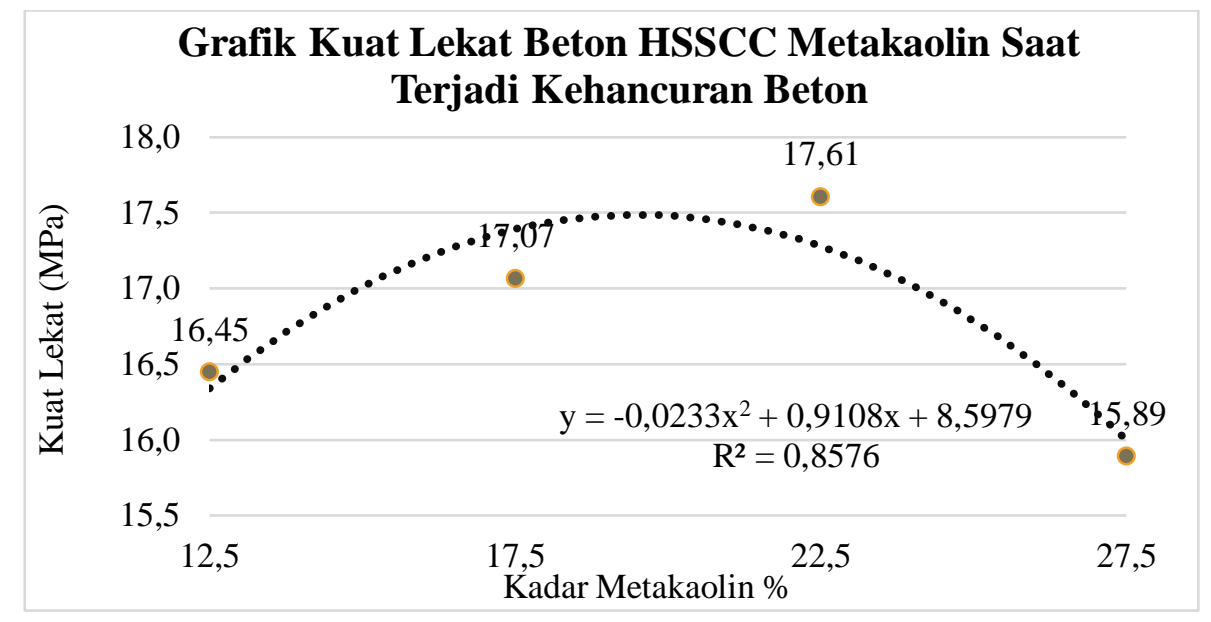

Gambar 7 Grafik Kuat Lekat Beton HSSCC Metakaolin Saat Kehancuran Beton

Tegangan lekat kritis adalah tegangan terkecil yang menyebabkan terjadinya sesar pada beton sehingga baja yang tertanam didalam beton bergeser sebesar $0,25 \mathrm{~mm}$, bila sesar beton lebih dari $0,25 \mathrm{~mm}$ maka beton dianggap sudah runtuh (ASTM C-234-91a). Penelitian ini mengambil data dari 2 fase yaitu saat terjadi kehancuran pada beton dan saat beton dan baja ulir mengalami sesar $0,25 \mathrm{~mm}$.

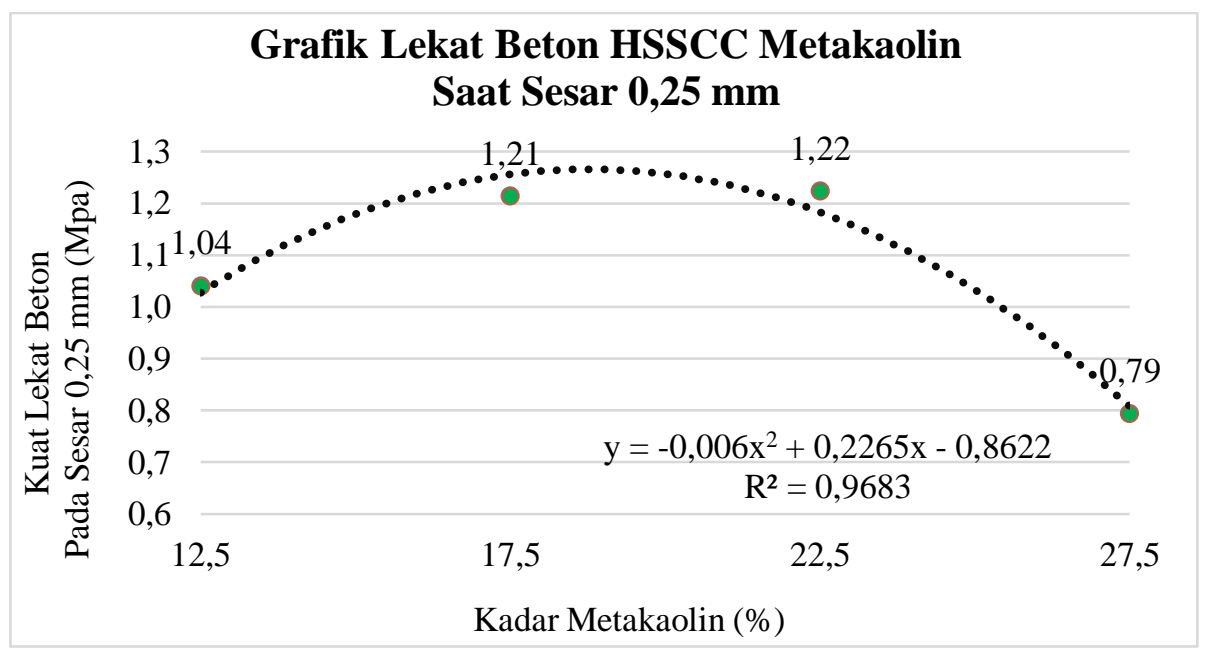

Gambar 8 Grafik Kuat Lekat Beton HSSCC Metakaolin Pada Sesar 0,25 mm

Gambar 7 dan 8 menunjukan bahwa penambahan metakaolin sebagai pengganti semen meningkatkan nilai kuat lekat beton. Nilai kuat lekat maksimum ada pada saat kadar metakaolin 22,5\%. Pada penggantian metakaolin kadar $27,5 \%$ nilai kuat lekat mengalami penurunan dari beton kadar metakaolin 22,5\% tetapi nilai kuat lekat betonnya masih diatas beton tanpa metakaolin. Berdasarkan hasil analisa bahwa garis regresi yang terbentuk dari grafik adalah garis regresi kurva parabola, persamaan garis regresi untuk mengetahui persentase penambahan komposisi metakaolin yang optimum. Persentase komposisi metakaolin terhadap kuat lekat beton yang optimal dicapai pada komposisi 19,55 \% dengan kuat lekat beton saat beton hancur yang optimum sebesar 17,49 MPa. Persentase 
komposisi metakaolin terhadap kuat lekat beton yang optimal dicapai pada komposisi 18,88 \% dengan kuat lekat beton saat sesat $0,25 \mathrm{~mm}$ yang optimum sebesar 1,27 MPa.

Peningkatan kuat lekat beton karena adanya penambahan metakolin dipengaruhi oleh beberapa faktor, salah satunya adalah reaksi pozzolanik akibat penambahan metakaolin. Reaksi pozzolanik mengubah $\mathrm{Ca}(\mathrm{OH})_{2}$ menjadi kalsium silikat hidrat (CSH) tambahan yang dapat meningkatkan kekuatan tekan dan tarik, serta daya rekat dalam beton melalui reaksi kimia.

Metakaolin adalah mineral yang paling reaktif dari semua pozzolan dan bersama dengan kalsium hidroksida (produk sampingan yang tidak diinginkan dari proses hidrasi semen) akan membentuk pengikat seperti kalsium silikat hidrat (CSH).

\begin{tabular}{|c|c|c|}
\hline C3S, C2S & $+\mathrm{H} 2 \mathrm{O}$ & $\mathrm{Ca}(\mathrm{OH}) 2$ \\
\hline Semen & + Air & $=>$ kalsium silikat hidrat + kalsium hidroksida \\
\hline $\mathrm{CA}(\mathrm{OH}) 2$ & $+\mathrm{Al} 2 \mathrm{O} 3.2 \mathrm{SiO} 2$ & $=>$ C-S-H + C2ASH8, C4AH13, C3AH6 \\
\hline Kalsium hic & da + Metakaolin & $=>$ kalsium silikat hidrat + kristal \\
\hline
\end{tabular}

Metakaolin juga berperan sebagai penutup rongga karena bertambahnya senyawa CSH yang mengisi pori-pori halus dalam pasta semen (Filler Effect) sehingga meningkatkan kepadatan campuran beton dan menurunkan permeabilitas beton secara substansial. Reaksi Pozzolanik meningkatkan daya tahan beton dan meningkatkan resistensi terhadap serangan kimia dan reaksi alkali silica karena reaksi $\mathrm{Ca}(\mathrm{OH})_{2}$ terhadap klorida, karbon dan sulfat yang dapat menurunkan kualitas beton dan membuat korosi pada beton bertulang terhambat sesuai dengan penelitian Metakaolin Pozzolanic Material For Cement in High Strength Concrete, Sanjay N. Patil.

\section{KESIMPULAN}

Berdasarkan hasil pengujian, pengolahan data, dan evaluasi yang telah dilakukan, kajian kuat lekan mutu tinggi memadat mandiri dengan variasi komposisi metakaolin dapat disimpulkan sebagai berikut :

1. Pada campuran beton mutu tinggi memadat mandiri, penambahan variasi metakaolin meningkatkan kuat lekat bila dibandingkan dengan beton dengan kadar metakaolin $\%$. Dalam campuran beton ini, nilai kuat lekat maksimum terjadi saat penambahan variasi metakaolin kadar 22,5\% sebagai pengganti semen. Penambahan metakaolin terhadap kuat lekat saat beton hancur yang optimal yaitu kadar 19,55 \% dengan nilai kuat lekat 17,49 MPa.Penambahan metakaolin terhadap kuat lekat pada sesar $0,25 \mathrm{~mm}$ yang optimal yaitu kadar 18,88 $\%$ dengan nilai kuat lekat 1,27 MPa.

2. Penambahan variasi metakaolin pada campuran beton mutu tinggi memadat mandiri menurunkan workability beton. Penambahan metakaolin kadar 12,5\% dan 17,5\% dari berat semen tidak memenuhi syarat parameter fillingability, sedangkan penambahan metakaolin kadar 22,5\% dan 27,5\% tidak dapat diuji parameter fillingability dikarenakan diameter sebaran tidak memenuhi standar EFNARC 2002.

\section{REFERENSI}

Ahmad, Emir. 2017. “Kajian Pengarub Variasi Komposisi Metakaolin Terhadap Parameter Beton Memadat Mandiri dan Kuat Tekan Beton Mutu Tinggl”. Universitas Negeri Sebelas Maret, Surakarta.

Anonim. 1991. "SK SNI T-15-1991-03 Tata Cara Pembuatan Campuran Beton Normal”. Departemen Pekerjaan Umum, Yayaan Lembaga Penyelidikan Masalah Bangunan, Bandung.

Anonim. 1991. "ASTM C234-91 a Standard Test Method for Comparing Concretes on the Basis of the Bond Developed with Reinforcing Steel'

Clara, Merin. 2013. "Strength Properties Of Concrete Spesimens With Metakaolin And Methylcellulose". Structural Engineering Sree Buddha College of Engineering, India.

Dipohusodo, Istimawan. 1994. “Struktur Beton Bertulang”. Gramedia Pustaka Utama, Jakarta.

Anonim. 2005. "EFNARC Specification and Guidelines For Self-Compacting Concrete".

Patil, S.N., Gupta, A.K., dan Deshpande, S.S. 2012. "Metakaolin- Pozzolanic Material For Cement in High Strength Concrete”. Dept. of Civil Engg., Dr. JJMCOE, Jaysingpur, M.S. India

Anonim. 1971. "PBI NI-2 Peraturan Beton Bertulang Indonesia". Departemen Pekerjaan Umum, Bandung.

Rachman. 2009. "Kuat Lekat dan Panjang Penyaluran Baja Polos pada Beton dengan Campuran Metakaolin, Slag, dan Kapur Padam sebagai Pengganti Semen”. Universitas Negeri Sebelas Maret, Surakarta. 
Rusyandi, Kukun. 2012. "Perancangan Beton Self Compacting Concrete dengan Penambaban Fly Ash dan Structuro". Jurnal Konstruksi, Garut. 